\title{
Potential Impact of the Current and Future Climate on the Yield, Quality, and Climate Suitability for Tea [Camellia sinensis (L.) O. Kuntze]: A Systematic Review
}

\author{
Sadeeka Layomi Jayasinghe ${ }^{1,2, *(\mathbb{D})}$ and Lalit Kumar ${ }^{1}$ (D) \\ 1 School of Environmental and Rural Science, University of New England, Armidale, NSW 2351, Australia; \\ lkumar@une.edu.au \\ 2 Faculty of Animal Science and Export Agriculture, Uva Wellassa University, Passara Road, \\ Badulla 90000, Sri Lanka \\ * Correspondence: ljayasi2@myune.edu.au or sadeekalj@gmail.com
}

check for updates

Citation: Jayasinghe, S.L.; Kumar, L. Potential Impact of the Current and Future Climate on the Yield, Quality, and Climate Suitability for Tea

[Camellia sinensis (L.) O. Kuntze]: A Systematic Review. Agronomy 2021, 11,619. https://doi.org/10.3390/ agronomy11040619

Academic Editor: Francisco

Manzano Agugliaro

Received: 8 February 2021

Accepted: 22 March 2021

Published: 24 March 2021

Publisher's Note: MDPI stays neutral with regard to jurisdictional claims in published maps and institutional affiliations.

Copyright: (c) 2021 by the authors. Licensee MDPI, Basel, Switzerland. This article is an open access article distributed under the terms and conditions of the Creative Commons Attribution (CC BY) license (https:/ / creativecommons.org/licenses/by/ $4.0 /)$.

\begin{abstract}
Even though climate change is having an increasing impact on tea plants, systematic reviews on the impact of climate change on the tea system are scarce. This review was undertaken to assess and synthesize the knowledge around the impacts of current and future climate on yield, quality, and climate suitability for tea; the historical roots and the most influential papers on the aforementioned topics; and the key adaptation and mitigation strategies that are practiced in tea fields. Our findings show that a large number of studies have focused on the impact of climate change on tea quality, followed by tea yield, while a smaller number of studies have concentrated on climate suitability. Three pronounced reference peaks found in Reference Publication Year Spectroscopy (RYPS) represent the most significant papers associated with the yield, quality, and climate suitability for tea. Tea yield increases with elevated $\mathrm{CO}_{2}$ levels, but this increment could be substantially affected by an increasing temperature. Other climatic factors are uneven rainfall, extreme weather events, and climate-driven abiotic stressors. An altered climate presents both advantages and disadvantages for tea quality due to the uncertainty of the concentrations of biochemicals in tea leaves. Climate change creates losses, gains, and shifts of climate suitability for tea habitats. Further studies are required in order to fill the knowledge gaps identified through the present review, such as an investigation of the interaction between the tea plant and multiple environmental factors that mimic real-world conditions and then studies on its impact on the tea system, as well as the design of ensemble modeling approaches to predict climate suitability for tea. Finally, we outline multifaceted and evidence-based adaptive and mitigation strategies that can be implemented in tea fields to alleviate the undesirable impacts of climate change.
\end{abstract}

Keywords: climate change; climatic factors; climate suitability; tea; quality; yield

\section{Introduction}

Plants of Camellia sinensis are the botanical source for the world's most-consumed nonalcoholic beverage-tea. The tea plant originated in south-western China around 5000 years ago and is now grown in over 58 countries with an estimated area of 4.37 million ha of land [1]. China, India, Kenya, and Sri Lanka are the leading tea producers in the world. Tea is being manifested as a vital part of the economy, rural development, food security, and poverty alleviation in many developing nations while quenching the thirst of 4.5 billion consumers around the globe [2]. The tea industry is anticipated to grow at a compound annual growth rate (CAGR) of about $4 \%$ to $5.5 \%$ from 2017 to 2024 [1,2]. The retail value of the world tea market was estimated at around USD 50 billion in 2017 and is projected to grow to over USD 73 billion by 2024 [2]. Therefore, a concerted effort should be made to harness the optimal benefits of the tea sector and downstream production lines in the future, even with the expected global challenges. 
Climate change, triggered by global warming, has been identified as a major challenge across the globe. In this context, the entire globe has experienced a striking surge in changing climate that is projected to increase at a significant pace in the future, with an unforeseen influence on agriculture, including that of tea. Climate change is defined as a change in the statistical properties, including averages, variability, and extremes, of the climate system that persists for several decades or longer [3]. The future climate will lead to an increase in adverse impacts across the globe. The changes in the global average temperatures by 2100 are predicted to be within the range of 1.1 to $5.4{ }^{\circ} \mathrm{C}$. The amount and intensity of precipitation will differ considerably by region, with an exponential rise in some areas and a decline in others [4]. The level of carbon dioxide $\left(\mathrm{CO}_{2}\right)$ has gradually risen from 280 parts per million (ppm) in the preindustrial period to 408 ppm currently and is projected to further increase up to approximately $800 \mathrm{ppm}$ by 2100 . Furthermore, wind and precipitation associated with tropical storms are likely to increase in intensity [4].

As tea plants have a long life span, the literature highlights the numerous decadal impacts of climate change, including stresses such as severe drought, uneven and heavy precipitation, increased temperatures, elevated $\mathrm{CO}_{2}$ concentrations, and other extreme weather events, including floods, frosts, and storms [5,6]. Moreover, climate changerelated biotic (i.e., pests and diseases) and abiotic stressors (i.e., UV irradiation, nutrient deficiency, and ozone depletion) affect the sustainability of climate-smart tea systems [7,8]. In tea-producing areas, agrometeorological conditions are experiencing variability with climate change. Uncertain and less predictable climate scenarios may no longer satisfy the ecophysiological requirements of tea, thus posing risks, threats and limitations, as well as advantages in some locations for the tea sector.

The impacts of climate change on the tea yield have already been broadly investigated and include irreversible yield losses, impacts on regional economies, and the threatening of millions of livelihoods of humans in many nations $[9,10]$. However, studies related to the impact of the current and future climate on the tea yield have only recently been published, so there are few pieces of scientific literature in the popular databases on this topic compared to other crops. Moreover, tea accounts for 35\%-50\% of secondary metabolites on a dry weight basis; these metabolites are also vulnerable to climatic variables altering phytochemical and organoleptic (texture, color, taste visual appeal, aroma) properties, which has divergent impacts on market prices, consumer demand, and the psychological implications of tea consumers across nations [11]. Considerable research has recently been conducted to cover this research topic, but the reviews are limited and still emerging. A systematic review was undertaken by Ahmed et al. [11], seeking the impact of environmental variables on tea quality previously, but that review did not look at the impact of future climate on tea quality. Overall, no previous studies include both the impacts of environmental variables on tea quality at present and how this quality may change under future climate.

In line with the altered climate and its related consequences, shifting and changing (i.e., gain/loss) suitable habitats have also been noted. Species distribution models (SDMs) are used to evaluate relationships between climate and species occurrences to predict possible changes in ecosystems $[12,13]$. In certain areas, climate change will be advantageous for tea plants, whilst in others it may not be desirable. Even though there is ample scientific literature addressing the effects of climate change on the tea yield or quality, the literature regarding the effect of climate change on the climate suitability for tea has been largely neglected.

The thematic content of publications can be visualized using keywords/items of the related topics, and co-occurrence item density maps are becoming popular in systematic reviews that mirror the density of the items in the bibliography [14]. The historical context, as well as the influential reference of a particular topic, can be detected by Reference Publication Year Spectroscopy (RPYS) based on the cited reference in the bibliography [7]. All-inclusive systematic reviews showcase landmarks of the specific fields of research that aid researchers in understanding the contribution of other authors to a similar topic, as well as the evaluation and progress of a particular topic over time. 
Holistic reviews on the impact of the current and future climate on tea for addressing the three important pillars of the tea sector-yield, quality, and climate suitability-have remained limited. In addition, implementing proper adaptation and mitigation strategies in the tea sector is a pressing need in the face of climate change. To identify and bridge the above knowledge gaps, in a first ever attempt, our study objectives were to synthesize reviews based on three queries: (1) What are the impacts of the current and future climate on the yield, quality, and climate suitability for tea?; (2) What are the historical roots and most frequently cited and influential papers on the aforementioned topics? and (3) What are the adaptation and mitigation strategies that can be implemented in tea fields to alleviate the adverse effects of climate change?

As a versatile sector that has socio-cultural and economic importance, the aforementioned topics should be given high significance in future avenues of the tea sector. Such systematic reviews can be exploited as useful tools to initiate scientific studies in the future. Furthermore, an exploration of tea's potential response to the current and future climate may be a successful strategy to form policies and decisions for the future reinforcement of climate-resilient tea systems. Filling the knowledge gap in the existing literature and raising awareness of the holistic picture of how climate change impacts the tea yield, quality, and climate suitability are crucial in order to achieve sustainable tea production, embracing multidisciplinary mitigation and adaptation approaches in the future.

\section{Materials and Methods}

\subsection{Data Compilation}

In order to address the study objectives, Preferred Reporting Items for Systematic Reviews and Meta-Analyses (PRISMA) [15] searching techniques were used, presenting an evidence-based approach for conducting systematic reviews (PRISMA procedure given in the Supplementary Figure S1). The Guidelines for Systematic Review in Conservation and Environmental Management and a systematic mapping process (http:/ / www.environmentalevidence.org/SR35.html, accessed on 17 September 2020) were taken into consideration when designing a systematic review protocol to address the targeted queries.

\subsection{Establishing a Review Team and Stakeholders}

The phases of the systematic review included independent repeatability testing involving two or more participants as one person is unlikely to have all the skills needed to execute all phases of the review. Subject experts within the review teams had to be carefully considered as they may have contributed biased opinions based on their expertise [15]. Stakeholders' contributions and their expertise may be required to outline the scope of the systematic review and ensure its relevance. However, a lack of evidence remains about the methods used to select review and stakeholder teams in systematic reviews. As per the systematic medical review guidelines, the team should typically consist of two reviewers, one tiebreaker, one or more stakeholder, and a statistician should be included when it is a meta-analysis (https:/ /libguides.utoledo.edu/sysrev, accessed on 15 September 2020). Accordingly, the team assembled for the present study consisted of review members $(n=2)$ and stakeholders $(n=3)$ teams, and further details are provided in the Supplementary Table (Table S1). All members were selected from multidisciplinary fields as stakeholders with experience in the various subjects (Table S1).

\subsection{Setting the Scope, Databases, Coding, and Inclusion Criteria}

The review team decided on and finalized the objectives and scope of the study with the aid of stakeholders' views. According to Table 1, tea (Camellia sinensis) was the subject or study unit of the present review. The intervention was climate change, with a special emphasis on future climatic conditions. As there were limited published works directly examining future climate effects on yield, quality, and climate suitability habitats for tea in 
our preliminary search, climatic factors from the current climate/baseline were assessed as a comparator.

Table 1. Elements included in the present systematic review.

\begin{tabular}{cc}
\hline Question Element & Definition \\
\hline Subject & Unit of study: tea (Camellia sinensis) \\
Intervention & Impact of future climate/climate change \\
Outcome & Tea yield, quality and climate suitability \\
Comparator & Current climate [s the intervention being compared with \\
no intervention?]
\end{tabular}

Two databases, namely the Web of Science (WoS, provided by Clarivate Analytics, accessed on 10 September 2020) and Scopus (provided by Elsevier, accessed on 11 September 2020), were used to find the key studies aligned with the study objectives. A combination of generic and subject-related fields defining the setting of the research were coded and are given in the Supplementary Table (Table S2). The inclusion criteria were established through consultation with the stakeholders, depending on the key element of systematic study. The inclusion criteria were identified, and a pilot study/trial run was conducted to test the inclusion criteria. This is an essential step in finding relevant information and maintaining the specificity of the review. During the iterative process, the inclusion criteria were refined to select evidence-based articles published in the English language from 1990 to 2020 (Table S2). The PRISMA screening procedure was followed to report items in the systematic review (Figure S1).

\subsection{Screening Evidence and Supporting Information}

The "Sysrev" software (version 1.0, Insilica Limited Liability Company, USA, http:/ / systematicreviewtools.com/tool.php?ref=Sysrev, accessed on 11 November 2020) available in a systematic toolbox and Endnote (version X9, Clarivate Analytics, Philadelphia, PA, USA) were used to screen relevant articles from the total number of articles. Out of 3066 articles, 2304 were excluded due to being conference proceedings, nonEnglish, or duplicates. Next, both the review panel (L.K. and S.J.) and stakeholders (B.S., P.K. and C.F.) (Table S1) screened the selected records of 762 papers to avoid reviewer bias in identifying articles. Discrepancies of addition or omission of records were discussed by the entire panel to resolve any ambiguities and 162 full-text articles which were related to the review question were selected for inclusion in the present review (Table S3). Some articles $(n=35)$ were again omitted when articles were irrelevant and, full-text articles were unavailable (one article only), as well as when articles appeared to be relevant, but full texts could not be accessed, resulting in a total of 126 articles (Figure 1 and Table S3). 


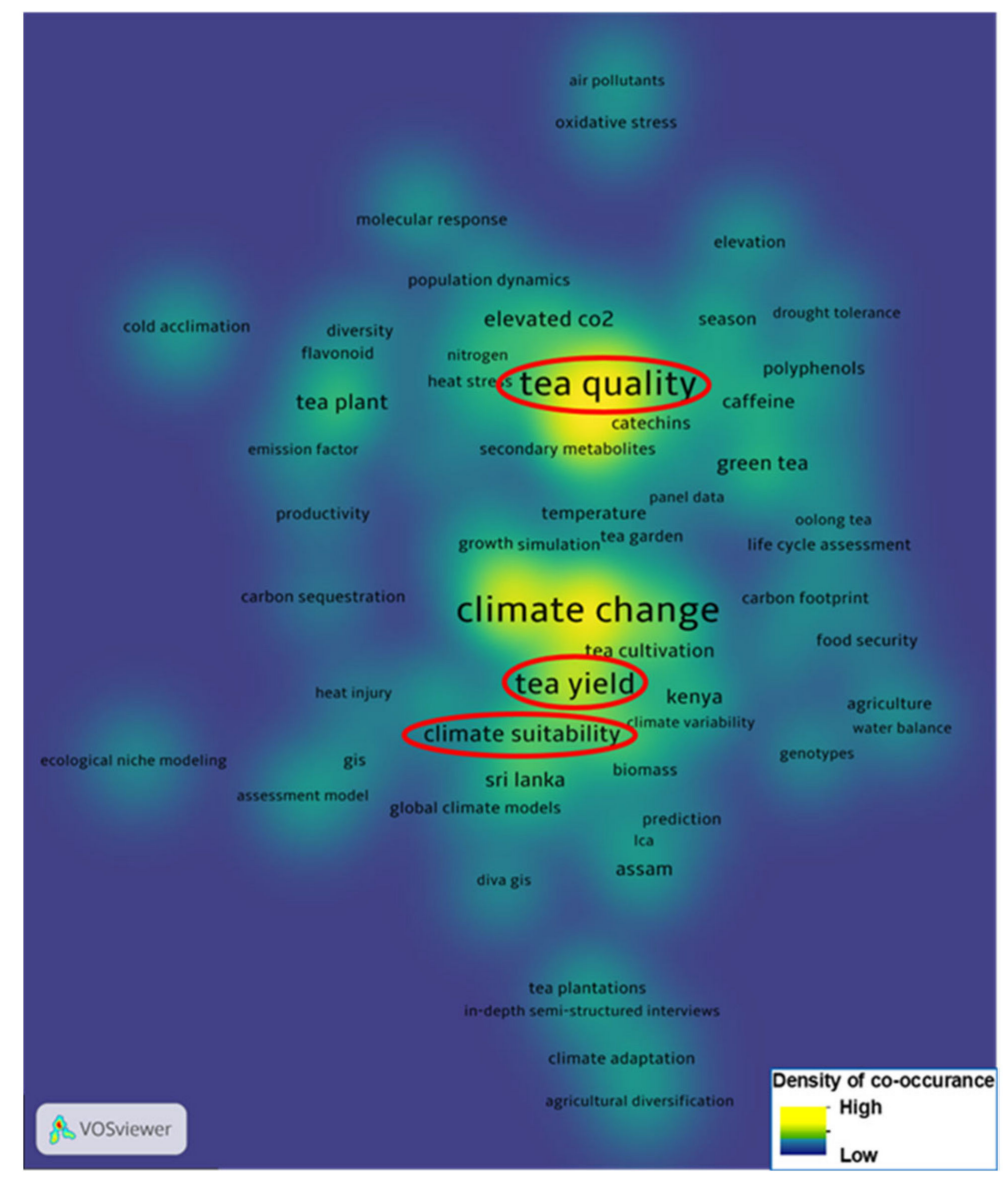

Figure 1. Visualization of the co-occurrence density of keywords from 762 papers on climate change and tea (Camellia sinensis). Note: As a threshold level, two nodes were taken.

\subsection{Keyword Visualization, Historical Roots, and Cited References (CRs) Analysis}

The VOSviewer software 1.6.5 (Leiden University, Leiden, Netherlands, http:/ / www. vosviewer.com, accessed on 15 November 2020) was used to map the keywords of the final set of selected full-text articles and a co-occurrence density approach was followed for visualizing corresponding key words on the map. The historical origins and the most frequently cited references of the selected topics were examined using CitedReferencesExplorer with a bibliometric tool called Reference Publication Year Spectroscopy (RPYS available in CRExplorer-version 1.9, Germany, http:/ / www.crexplorer.net, accessed on 20 September 2020) [7].

\subsection{Extracting and Recording Data}

The final set of articles were read by the review team (Table S1) and grouped in to three categories based on the climatic impact on: (1) yield (Table S4), (2) quality (Table S5); and (3) climate suitability habitats of tea (Table S6). Data were placed in multiple tables highlighting titles, climatic factors, the country/region, and the key findings. The second member in the review panel reviewed extracted data and verified the appropriateness and relevancy. There were large discrepancies between different studies, as different studies harnessed different approaches, measures, cultivars, and study locations. The change directions (decrease, increase, or no change) of the current and future climate on the yield, quality, and climate suitability habitats of tea were assessed where necessary. 


\section{Results}

\subsection{Keyword Visualization (Co-Occurrence Density Visualization)}

Figure 1 shows the keyword map based on the 762 selected papers on climate change and tea production. The weight that was specified to the color of a certain cluster was determined by the number of keywords belonging to that cluster in the vicinity of the point ranging from high (yellow) to low (blue). In terms of co-occurrence, the gap between two main words is inversely proportional to the similarity. The keywords (nodes) $(n=168)$ on the map were assigned to specific clusters based on an algorithm. The node of "climate change" appeared as the most prevalent keyword, with a high co-occurrence density, followed by "tea quality" and "tea yield". It is clear that the climate suitability for tea has the lowest co-occurrence density, indicating that a lower number of studies have been performed on this topic (Figure 1).

\subsection{Historical Roots and Cited References (CRs) Analysis}

The outcome of the reference Publication Year Spectroscopy (RPYS) that can be used to identify historical roots and classify peak papers in the specific discipline is shown in Figure 2. The spectrogram displays the dissemination of the cited references over their publication years within the time frame of 1920-2020. The CRExplorer (version 1.9, Germany, http: / / www.crexplorer.netRPYS, accessed on 20 September 2020) identifies the relevant years of the highly cited references in the table provided alongside the spectrogram. The number of cited references per reference publication year is shown by the blue color curve, and the deviation from the median of the number of cited references is shown by the red color curve for the two previous, current, and two following years $(t-2 ; t-1 ; t+1$; $\mathrm{t}+2$ ) (Figure 2)

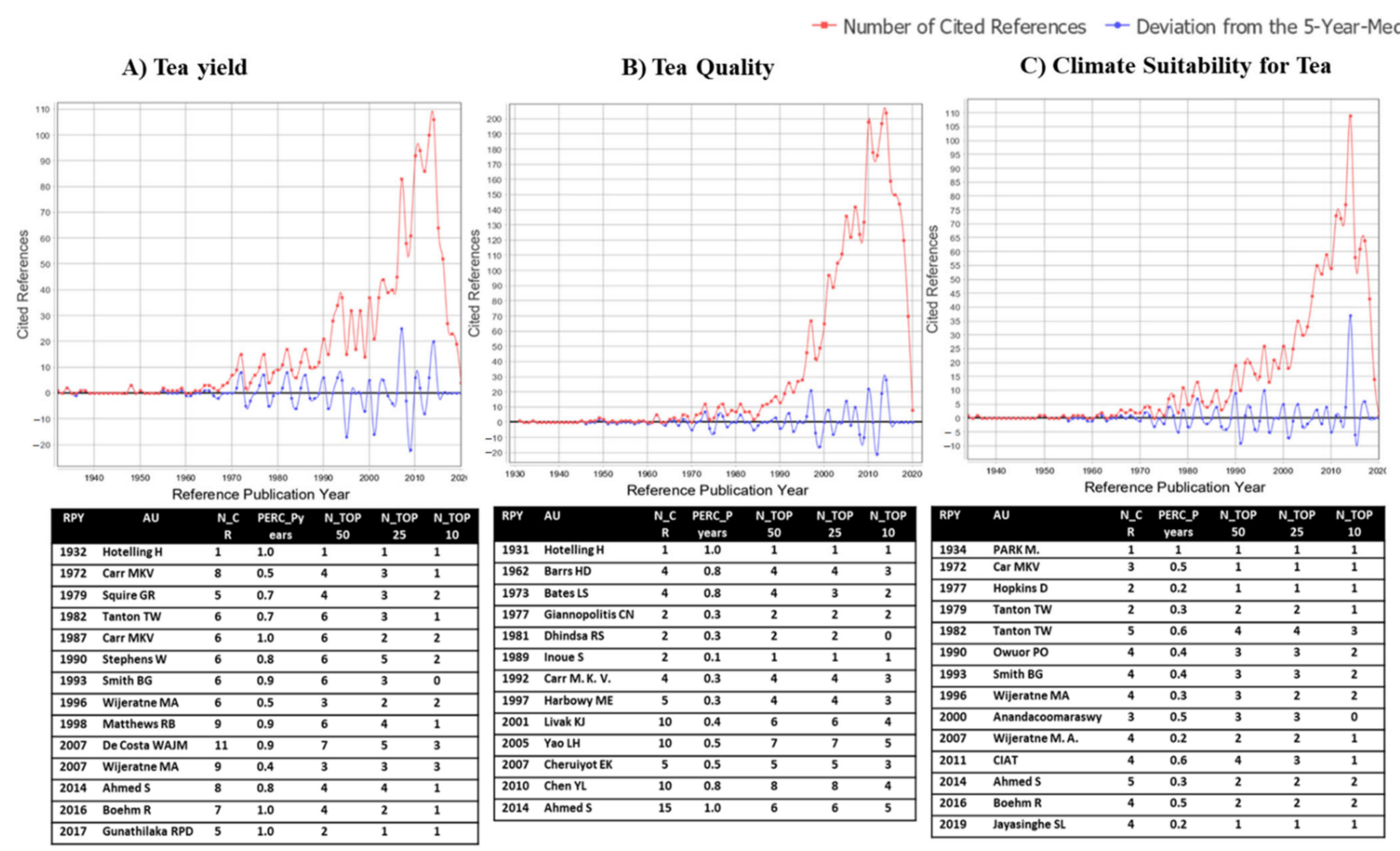

Figure 2. The Reference Publication Year Spectroscopy (RPYS) spectrograms and the distribution by reference publication year for 1930-2020 of the main references cited, based on the subjects' entitled effect of climate change on the (A) yield (B) quality and (C) climate suitability for tea, with the historical roots of the relevant topics. Note: Highly cited papers included in the spectrogram, RPY: Reference publication year, N_CR: Number of cited references, PERC_Pyear: Percent in year, N_top 50: Top 50\% cited reference, N_TOP 25: Top 25\% cited reference, N_TOP 10: Top 10\% cited reference. 
The historical roots of the field are indicated in the early peaks of the reference publication years. Hotelling [16], Hotelling [17], and Park [18] were credited for providing the first fundamental framework for initiating work related to the impact of climate change on the yield, quality, and climate suitability for tea, respectively (Figure 2). Significant publications in the field of research are shown in the RPYS as high peaks. Accordingly, Wijeratne [19], Ahmed et al. [20], and Adhikari et al. [21] are indicated as the seminal papers linked to the effect of climate variability on the (a) yield, (b) quality, and (c) climate suitability of tea, respectively, based on the number of citations from 1930 to 2020 (Figure 2). Among significant studies on the tea yield, two key findings were reported by Wijeratne [19]: (1) Temperature increases, vapor pressure deficit, and soil moisture deficit at low elevations would adversely impact the growth and yield of tea; and (2) tea cultivation is clearly vulnerable to altered climatic conditions at low and mid-elevations. The publication by Ahmed et al. [22] is based on the impacts of pest infestations and water availability on tea growth and secondary metabolites that demonstrate the consequences of extreme climates on tea quality. Adhikari et al. [21] identified how tea cultivation would be distributed with respect to the changing climatic conditions.

\subsection{Climate Change and the Tea Sector}

\subsubsection{Effects of Climate Change on the Tea Yield}

A few studies were specifically linked to the topic of the effect of climate change on the tea yield and quality, so the inclusion criteria were updated, and the impact of each climatic factor was taken into account. According to our searched database, we found 42 research articles related to the topic of the effects of climatic fluctuations on the tea yield.

\section{Temperature}

Around 50\% (22 of 42) of the studies found that temperature was prevalent in previous studies impacting the tea yield. Many tea-producing countries are experiencing yield reductions with rising temperatures, including Sri Lanka [10,19,23], Kenya [24-26], India [27-29], and China [30,31] (Table S4).

For example, Duncan et al. [27] found that monthly temperatures above $26.6{ }^{\circ} \mathrm{C}$ had an adverse effect on the tea yield, and an additional one degree of temperature at an average monthly temperature of $28{ }^{\circ} \mathrm{C}$ would reduce the yield by $3.8 \%$ in Assam, India. Wijeratne et al. [23] also found that the yield tended to decline in Sri Lanka with an increasing temperature in higher mean temperature regions $\left(>25-26{ }^{\circ} \mathrm{C}\right)$. Okoth [32] reported that an increase in the maximum temperature was found to create a potential decrease in tea production in most of the tea-growing areas in the world. However, Han et al. [33] found that, in a region or season with low temperatures, an increase in temperature would increase the yield. Furthermore, Rao [34] indicated that if the night temperature drops below $5^{\circ} \mathrm{C}$ and humidity below $10 \%$, this leads to a lower level of tea production. He also mentioned that the occurrence of heatwaves adversely affected tea crops in Himachal Pradesh, India, and can cause damage of up to $50 \%$. Up to $40 \%$ tea yield loss is anticipated in Africa due to the decline in suitable areas caused by the temperature rise [21].

\section{Rainfall and Seasonal Effect}

The present review yielded 17 studies related to the impact of the climate fluctuations linked to the rainfall's effect on the tea yield (Table S4). Changes in rainfall of $1 \mathrm{~mm}$ caused $0.3-0.8 \mathrm{~kg}$ variations in tea per ha during the dry season [23]. Nine studies demonstrated that an uneven rainfall distribution and high/low intensities of rainfall significantly reduce tea production in many tea-producing countries, such as China [5,31], India [27,29,35,36], Kenya [26], and Sri Lanka [10,23]. Some studies showed that the relationship between rainfall and the tea yield is positive [32,37]; however, intense rainfall may lead to flooding, earth slips, or landslides, which deplete the fertility of top soils in tea fields, especially at high elevations, leading to a negative impact on tea yields [38,39]. Seasonal variation directly 
associated with climate change and the shifting of seasons can also drive shorter growing seasons, which decreases the yields of the first and second flush in tea fields $[5,23,36]$.

\section{Drought/Soil Water Content}

Nine studies were focused on how drought stress reduces the tea yield (Table S4). Generally, drought is responsible for $14 \%-20 \%$ yield loss and $6 \%-19 \%$ plant mortality in tea fields [40,41]. The drought in the Rift Valley, Kenya, in 2009, resulted in a 30\% reduction in the tea yield [42]. Moreover, the 1992 drought in Sri Lanka resulted in a 26\% reduction in tea yields [23].

\section{$\mathrm{CO}_{2}$ and $\mathrm{N}_{2} \mathrm{O}$}

It is apparent that the tea yield is positively correlated with elevated atmospheric $\mathrm{CO}_{2}[6,23,43-45]$. Elevated $\mathrm{CO}_{2}$ can increase photosynthesis and respiration and thereby increase the overall dry matter content in tea plants. However, Ahammed et al. [43] mentioned that even though the tea yield increases with elevated $\mathrm{CO}_{2}$, it weakens the tolerance and resistance mechanism of tea plants to some biotic stresses, including pests and pathogens, posing a serious threat to entire tea systems in the future.

As greenhouse gases, both $\mathrm{CO}_{2}$ and $\mathrm{N}_{2} \mathrm{O}$ can have a considerable impact on the tea yield. Wu et al. [46] showed that the application of $\mathrm{N}$ fertilizers is a main source of global anthropogenic $\mathrm{N}_{2} \mathrm{O}$ emissions, and the application of high rates of controlled-release $\mathrm{N}$ fertilizer will reduce the tea yield by $6.8 \%$.

\section{Light/Solar Radiation}

Two studies were found in relation to answering how changing light impacts the tea yield. In China, Boehm et al. [5] found that a 1\% decrease in solar radiation during the previous growing season was correlated with a $0.554-0.864 \%$ yield reduction in the tea plantation in the next year. Showing the opposite response in Taiwan, Chen et al. [30] found that the number of leaves and weight of tea shoots increase with a unit increment of solar radiation and increase the final tea yield.

\section{Future Predictions Related to Climate Change and the Tea Yield}

Ten studies forecasting the future tea yield using climatic parameters were found. Wijeratne et al. [23] projected that the yield would be decreased at lower elevations, but increased in areas of Sri Lanka with a cooler temperature at higher elevations by 2050. Tea production in Assam is expected to decline by up to $40 \%$ by 2050 due to climate change if mitigation and adaptation steps are not implemented [47]. Rigden et al. [25] predicted that the tea yield in Kenya would decrease by 5\% in 2040-2070 compared to the tea yield of 1990-2020 due to heat and water stress. Gunathilaka et al. [10] showed that the total tea production in Sri Lanka is predicted to decline by $7.7 \%, 10.7 \%$, and $22 \%$ under the medium emissions scenario by the three-time windows of 2026-2035, 2046-2055, and 2081-2090, respectively. Dutta [48] predicted that a change in the peak period of production (April to September) might occur in tea-growing areas in Assam, India, which may influence the tea yield under the prevailing conditions in 2050. Leary et al. [39] stated that the tea yield will increase in high elevated areas with global warming. Beringer et al. [24] projected that tea yields will increase in Japan, Turkey, China, and Vietnam by 2\%, 14\%, $20 \%$, and 27\%, respectively, under Representative Concentration Pathway (RCP) 2.6 of five different global climate models by 2069-2099, while Sri Lanka, Indonesia, Kenya, and some regions in Bangladesh are expected to exhibit significant yield reductions by 2069-2099 under the same climate models (Table S4). Some researchers have built models (e.g., LundPotsdam-Jena managed Land (LPJmL), CUPPA model, Department of Natural Resources Management, Cranfield University, Silsoe, Bedfordshire) to assess the relationship between climatic factors and the tea yield, which can be considered for predicting tea yields in the future with high model performances (coefficient of determination $\left.\left(R^{2}\right)>0.8\right)[24,49,50]$. 


\subsubsection{Tea Quality}

Out of 127 studies, 57 studies addressed tea quality and its relation to climate change. The impacts of climate change on tea quality are more vivid and complex.

\section{Season/Rainfall}

Clearly, seasonality has substantial effects on tea chemistry, as the search yielded 15 studies. It has been reported that climate change poses many changes to the seasonality of climate and has adverse impacts on tea quality [11,51]. The findings of these studies demonstrated that concentrations of polyphenols, volatile compounds, and caffeine are higher during spring seasons than monsoon seasons [33,51-54], while the theanine content is low in the spring season [6,55]. However, Lee et al. [56] stated that, during the spring season, a high level of precipitation induces theanine synthesis in green tea. Ahmed et al. [20,22,52] also mentioned that the secondary metabolites of catechin and methylxanthine were up to $50 \%$ lower during the summer, while the concentrations of total phenolic and antioxidant activity increased. However, the impact of the seasonality of the climate on the concentrations of biochemicals varies based on other factors, such as the cultivar and geography $[20,51]$. A prolonged monsoon season led to a decrease in the total catechins content in tea leaves, including Epicatechin gallate, Epigallocatechin, Epicatechin, and Epigallocatechin gallate [57]. Ahmed et al. [58] found that higher water availability for tea crops can increase total methylxanthine and phenolic concentrations while decreasing Epigallocatechin gallate concentrations. Furthermore, Kfoury et al. [51] indicated that teas harvested in the spring season contained attributes of fruity, floral, and sweet attributes compared to summer teas.

In response to climatic changes, the levels of the metal nutrient in tea also varied. Huang et al. [54] found that the concentrations of $\mathrm{Fe}, \mathrm{Ca}, \mathrm{Mg}, \mathrm{Mn}, \mathrm{Al}$, and $\mathrm{Ba}$ were higher in summer, and those of $\mathrm{Pb}, \mathrm{K}, \mathrm{Cu}, \mathrm{Zn}$, and $\mathrm{Na}$ were higher in spring and autumn. The study conducted by $\mathrm{Han}$ et al. [33] revealed that seasonal variation might affect $\mathrm{Pb}$ concentrations in tea shoots as per the order of spring $>$ autumn $>$ summer, and climate change may cause the maximum possible thresholds of the $\mathrm{Pb}$ concentration $(2 \mathrm{mg} / \mathrm{kg})$ to be exceeded in China in the future.

Drought

We found 15 studies related to drought linked to climate change and its effect on tea quality, which presented dissimilar findings. High antioxidant activity was observed in tea leaves with higher polyphenol and catechin levels during a drought period [58-60], while some other studies showed a decline in these compounds with drought [40,61]. Wang et al. [62] indicated that drought stress significantly reduces the total polyphenols, catechins, caffeine, theanine, and free amino acids and increases the total flavonoids, severely decreasing the quality of tea. Chakraborty et al. [63] and Wang et al. [64] showed both an increase and decrease in phenolic compounds in tea leaves with drought stress as these compounds initially increased with drought stress and gradually decreased with prolonged drought stress. Cao et al. [65] revealed that under the soil moisture content of $53.9 \%$, tea leaves contain the highest concentrations of aromatic compounds, while the lowest values are recorded under a $100 \%$ soil moisture content. Severe drought generally inhibits the induction of methyl salicylate, which induces a defense mechanism against insect attack and thus brings changes in tea quality [66].

A recent study conducted by Chaeikar et al. [67] demonstrated that drought stress tends to decrease the total polyphenol and total ash content while increasing proline and total sugar in tea leaves. Some studies have reported that the water content and chlorophyll levels are higher in tea plants exposed to drought stress. The external supplementation of $\mathrm{K}+$ alleviates drought stress in tea plants [68]. 


\section{Solar Radiation/Light}

It was found that polyphenols, some terpenoids, and phenolic volatile compounds in tea leaves increased with increased light intensity, while amino acids and the caffeine content decreased $[69,70]$. However, tea polyphenols showed the opposite trend with the duration of light, exhibiting a negative correlation with increasing sunlight hours [71]. Some studies demonstrated inconsistent accumulation patterns of phenolic acids and flavonols in tea seedlings in the presence of sunlight [72]. Zheng et al. [71] found that short-term irradiation of Ultraviolet B (UV-B) induced catechin production, while excessive long-term UV-B irradiation suppressed the total catechins levels in tea plants. The concentrations of Epigallocatechin gallate (EGCG) were high under appropriate levels of UV-B irradiation. Sano et al. [73] found that the chlorophyll a/b ratio, enzymes, antioxidant activities, total ascorbate level, and ascorbate/dehydroascorbate ratio were higher in high-light-treated plants than in shaded plants.

\section{Temperature}

According to the literature, we found both positive and negative effects of temperaturelinked climate change on tea quality. Temperature has a close association with elevation, where a higher elevation normally leads to a lower temperature and vice versa. Higher concentrations of (-)-epicatechin (EC), (-)-epicatechin gallate (ECG), catechins (C), (-)epigallocatechin gallate (EGCG), valine, alanine, isoleucine, leucine, and caffeine were present in tea leaves at a higher elevation with a cooler temperature, while recording a lower theanine content [56]. However, Wang et al. [57] revealed that (-)-epicatechin (EC), (-)-epigallocatechin (EGC), (-)-epicatechin gallate (ECG), and (-)-epigallocatechin gallate (EGCG) increased with an increasing temperature, but record lower (+)-catechin (C) with an increased temperature. Han et al. [33] found that the content of catechins was differentially changed with the temperature. In fact, epigallocatechin-3-gallate (EGCG) and epicatechin gallate (ECG) was decreased with a cooler temperature at a higher elevation, whereas epigallocatechin (EGC) and gallocatechin gallate increased [33]. In addition, amino acids, particularly theanine, arginine, serine, $\gamma$-aminobutyric acid, glutamic acid, and aspartic acid, as well as the catechin to TP ratio, increased in cooler temperatures while lowering the ratio of the total polyphenol content (TPC) to amino acid (AA). Kfoury et al. [74] also demonstrated that a $5{ }^{\circ} \mathrm{C}$ change in temperature due to elevation differences causes significant alterations in tea chemistry. Han et al. [33] demonstrated that after being exposed to heat stress, the proline content, activities of peroxidase (POD) and catalase (CAT), electrolyte leakage (EL), and malondialdehyde (MDA) content may increase in tea leaves.

\section{Carbon Dioxide}

We found 14 recently published studies related to the impact of atmospheric $\mathrm{CO}_{2}$ on tea quality. Among those studies, Ahmed et al. [11] reported a substantial increment in the soluble sugar content, sucrose and starch, total catechins, total polyphenols, (-)epigallocatechin (EGC), and (-)-epigallocatechin-3-gallate (EGCG) with an increased $\mathrm{CO}_{2}$ level, while the levels of caffeine and free fatty acid content decreased [6,45]. Li et al. [6,45] found that the levels of theanine and some free amino acids were higher under increased $\mathrm{CO}_{2}$, while in other studies, it was reported that the amino acid content was inversely associated with elevated $\mathrm{CO}_{2}$, which enhances the TPC/AA ratio in tea leaves [75]. Li et al. [45] showed that, compared to ambient $\mathrm{CO}_{2}$ levels, the defense-related biochemicals of salicylic and jasmonic acids increased in tea seedlings grown under elevated $\mathrm{CO}_{2} . \mathrm{CO}_{2}$ enrichment (750 mmol mol ${ }^{-1}$ for 90 days) resulted in increased carotenoids and chlorophyll a and b in tea leaves [44]. Under elevated $\mathrm{CO}_{2}$, tea leaves are enriched with nutrients and this tends to attract more sap-sucking insects, i.e., aphids, whiteflies, and planthoppers, as well as diseases such as anthracnose, brown blight, and dieback, to the system, which has numerous negative impacts on tea cultivation $[45,76]$. However, some studies demonstrated that 
leaf-eating insects are controlled and suppressed under increased $\mathrm{CO}_{2}$ due to a deficiency in the nutrients of their feeds $[77,78]$.

Future Predictions Related to Tea Quality and Its Relationship with Climate Change

No studies have thus far predicted and assessed how the future climate will influence the tea quality, except for studies on how elevated atmospheric $\mathrm{CO}_{2}$ levels and simulated acid rain (SAR) alter biochemicals in tea shoots [6,11]. In particular, some authors reported that elevated CO2 will have a more positive impact on the tea yield in the future $[6,45,52]$. Acid rain is another outcome caused by climate change, and Zhang et al. [79] demonstrated that tea plants affected by simulated acid rain (SAR) at $2.5 \mathrm{pH}$ produce metabolic disorders, alerting readers to the importance of maintaining quality tea in south China in the future. A recent systematic review was carried out by Ahmed et al. [11] to examine the environmental variables linked to climate change on tea quality; however, the impact of future climate on tea quality is less widely acknowledged. Overall, models predicting the future tea quality are lacking in the literature within the context of the changing climate.

\subsubsection{Habitat Distribution \\ Current Suitability Habitat Changes with Climate Change}

We found 28 studies that show the potential impacts of climate fluctuations on climate suitability for tea habitats in major tea-producing countries. Jayasinghe and $\mathrm{Ku}$ mar [80] found that the optimal, medium, and marginal climate suitability of the existing tea-growing areas in Sri Lanka, Kenya, India, and China is likely to change with an increased annual mean temperature, indicating gains, losses, and changes of suitability. Jayasinghe et al. [81] also assessed the land suitability for tea crops in Sri Lanka and found that Sri Lanka was occupied by $13.9 \%, 12.4 \%, 42.1 \%$, and $28.5 \%$ highly suitable, moderately suitable, low suitability, and unsuitable land cover, respectively, for tea cultivation. Jayathilaka et al. [82] examined the geographic shift of suitability, yield, and climate classes of tea in Sri Lanka. Kotikot et al. [83] estimated that extreme weather conditions, including hail and frost, affect up to one-third of the tea bushes in the Nandi Hills, which is one of the main tea-producing areas in Kenya. Deng et al. [84] suggested that the risk of tea plant heat injury (RTHI) increases with climatic warming and high values of RTHI were estimated for the tea fields in central Zhejiang province, China. The highly suitable, moderately suitable, and unsuitable areas for tea in Zhejiang Province, China, were found to be $27,550,42,725$, and $26,500 \mathrm{~km}^{2}$ and accounted for $28.5 \%, 44.1 \%$, and $27.4 \%$ of the study area, respectively [85]. Ngoc et al. [86] found that both temperature and precipitation in Con Cuong, Vietnam are relatively suitable for the tea plantations.

\section{Future Climate Suitability}

The present review suggests three main changes in climate suitability, as follows: (1) existing areas with climate suitability will be reduced with the future climate (loss $(-)$ );

(2) expanding climate suitability of existing areas with the future climate (gain (+ )); and

(3) shifting climate suitability of tea to new areas.

Providing examples for future loss (-)/gain (+) of climate suitability, Jayasinghe and Kumar [80] found that decreasing optimal tea suitability areas in Kenya, Sri Lanka, and China will face a suitability decline of $26.2 \%, 14 \%$, and $4.7 \%$, respectively by 2050 and $15.1 \%, 28.6 \%$, and $2.6 \%$, respectively, under the average of three RCPs of RCP2.6, RCP6.0, and RCP 8.5 by 2070 . However, climate change will bring a blessed future for the Indian tea sector, which will gain optimal suitability areas of $15 \%$ and $25 \%$ by 2050 and 2070 , respectively. Further, the same authors in 2019 showed a reduction in $10.5 \%, 17 \%$, and $8 \%$ in "optimal", "medium", and "marginal" suitability areas in Sri Lanka, respectively, in the future [81]. Adhikari et al. [21] reported that the number of suitable areas for tea in Africa is expected to decrease from the current $60 \%-80 \%$ to $20 \%-40 \%$ by 2050 . Ranjitkar et al. [87] found that the suitable habitats for tea were projected to be reduced by 2050 in Yunnan Province of southwest China. 
In addition, some studies showed that climate suitability at a low elevation will be lost to a greater extent, shifting tea cultivation to high elevations. For instance, Adhikari et al. [21] demonstrated that the optimum tea production zones are predicted to move towards high altitudes, while there will be declining climate suitability in existing tea-growing areas. Furthermore, Laderach and Eitzinger [88] stated that the current optimum tea-producing region at an altitude of 1500-2100 $\mathrm{m}$ above sea level (masl) will rise to an altitude of 2000-2300 masl by 2050. In Uganda, optimal tea-growing areas are expected to shift from the current 1450-1650 m above sea level to 1550-1650 m above sea level under the A2 storyline by 2050 [89]. The overall tea-growing areas are expected to decrease by 2050 due to the lack of high altitude areas in Uganda [89].

Some research also indicated that several existing tea-growing areas will no longer be suitable for tea in Sri Lanka [81,90], Kenya [25], Yunnan in China [87], East Africa [88,89], Assam in India [28,91], tea growing coastal lines in Korea [92], and Taiwan [93]. Rigden et al. [25] predicted that there is limited suitable land that would permit Kenyan tea production to be adapted to a changing climate. Moreover, increased rainfall in humid areas often contributes to increased runoff and degradation with a greater flood risk, which further creates undesirable conditions for tea [94].

Some studies indicated that if the climate is undesirable for tea plants in a particular area, tea habitats will shift to new suitable areas [9]. Reay [8] indicated that the likelihood of shifting tea cultivation to new areas is high due to changes in climate suitability in the near future. In Ecuador, Rivera-Parra and Peña-Loyola [95] predicted that there are more than 150,000 ha, especially in coastal provinces and in the foothills of the Andes, that could be transformed into high-quality tea plantations without executing major changes in ecological niches due to long-term climate change.

\subsection{Adaptation and Mitigation}

In the context of climate change, the tea system should address the two major challenges of adaptation and mitigation [96]. A few major mitigations and adaptation measures practiced in the tea sector were extracted and are outlined below.

In addressing mitigation strategies, tea factories reduce consumptions of energy, fuelwood, and diesel at the factory level, and quantify and monitor greenhouse gas emissions associated with operations [97]. As a mitigation measure, tea farmers are encouraged to increase and sequestrate the soil carbon content in tea fields (e.g., organic tea cultivation) as tea bushes have huge carbon sequestration potential and thereby mitigate the greenhouse effect. For instance, Pramanik and Phukan [98] quantified the global warming mitigation potential (GWMP) of an entire tea field, including both tea bushes and shade trees, presenting a value of $6.19 \pm 1.7 \mathrm{~kg} \mathrm{CO}_{2} \mathrm{KMTH}^{-1} \mathrm{yr}^{-1}$. The emission of greenhouse gases produced in tea soils can be reduced by reducing the excess application of nitrogen fertilizers, using slow-release nitrogen fertilizers and balanced fertilization, and increasing nitrogen use efficiency [46]. Other mitigation approaches in the review are to decrease deforestation and use bioenergy instead of fuel during tea manufacturing [97].

The cultivation of drought- and heat-resistant varieties that can survive in water stress conditions [38] and releasing improved climate-compatible or/and climate-resilient cultivars via genetic breeding are crucial adaptation measures, which consist of a diverse molecular regulatory mechanism linked to abiotic stresses [99]. For example, the cooperation of genes that are related to the heat shock transcription factor (Hsf) will give stamina for tea plants to face abiotic stresses [55]. Tea farmers adapt to Good Agricultural Practices (GAPs), such as agroforestry, mixed culture, crop rotation, contour farming, the planting of shade trees, and crop diversification to protect tea plants from the increasing temperature and heat stress, whilst reducing evapotranspiration, protecting them from frost, preventing soil erosion, and enhancing the soil fertility in tea fields $[100,101]$. Supplementation with $\mathrm{K}+$ to reduce drought stress and the application of the antitranspirant of Kaolin to the tea canopy to reduce transpiration $[38,68]$. Other adaptation options found in tea fields are oil conservation via mulching, cover cropping, and carbon sequestration through a nontil- 
lage process, organic agriculture, fertilizer manipulation, integrated nutrient management (INM) [100], and climate-smart landscape management (e.g., irrigation and water supply systems) [35].

Moreover, risk assessment tools (e.g., crop insurance, mutual funds, loan schemes, index insurance) have emerged as reliable criteria to minimize the farmers' risk and vulnerability caused by climate change. One promising way to address climate vulnerability is by introducing insurance schemes for their products, allowing tea growers to transfer or reduce their risks of climate challenges to financial institutions. Index-based agricultural insurance has been introduced to tea farmers in some tea-growing nations that pay farmers based on loss of assets and severity of damage caused by weather or extreme events [102]. For example, smallholder tea farmers in Sri Lanka secure their tea crop through crop insurance provisions introduced by the government, such as the Agricultural and Agrarian Insurance Board (AAIB) index insurance. It pays substantial cover to tea farmers as per the loss of assets and investment estimated by the predetermined index of rainfall level. The Sanasa Insurance company in Sri Lanka introduced index insurance for smallholder tea farmers in the Ratnapura district of Sri Lanka in 2012 [103]. The agrometeorological disaster index (AMDR) is popular in China as it mitigates the risk faced by smallholder tea farmers during the late spring cold season [104]. Crop insurances are widely welcomed by Kenyan and Rwandan tea growers [104].

In addition, organizing awareness programs on climate-smart management practices and adaptation measures highlighting research outcomes, with the active participation of all stakeholders, including researchers, tea advisory agencies, and tea workers [10] is an essential way of strengthening adaptation and mitigation measures.

\section{Discussion}

There has been a large upsurge in climate change across the world, and this will continue even more dramatically in the decades ahead [105], and tea systems are not exempt from these escalating adverse effects. This systematic review showcases current and future climate impacts on the yield, quality, and climate suitability for tea, while reporting the historical basis, the most influential research papers related to the above aspects, and the adaptation and mitigation strategies which other researchers have addressed, together in the same review.

Given this trend, across disciplines, we found that the impact of the current and future climate presents both advantages and disadvantages for tea, having multidimensional and multifaceted consequences. It is important to note that a lower number of studies have been conducted to address climate suitability for tea, as well as the impact of the future climate on the tea yield and quality (Table S2). The thematic maps with keywords (Figure 1) and Reference Publication Year Spectroscopy (RPYS) (Figure 2) have recently been largely exploited by researchers in systematic reviews. As per Figure 2, historical foundations linked with the study topics were investigated, and three pronounced reference peaks were found in RPYS that represent the most significant papers by Wijeratne [19], Ahmed et al. [20], and Adhikari et al. [21] linked to the yield, quality, and climate suitability for tea, respectively. Within the corresponding citation network, the reference counts $(\mathrm{N}$ $\mathrm{CR}$ ) are comparatively small (Figure 2); as all citations included in the WoS database were considered, this may be due to the fact that the research questions addressed here are only starting to be researched.

\subsection{Tea Yield}

According to the previous evidence gathered from our search (42 studies) (Table S4), climate change poses both pros and cons for the growth and development of tea and is anticipated to have a considerable impact on the tea yield (Figure S2). As a C3 crop, tea plants receive advantages of an increment of $\mathrm{CO}_{2}$, temperature, and rainfall amount, while also receiving an adverse impact from the decrease in sunny days, rainy days, and relative humidity, and increased extreme climatic events, such as drought, floods, 
and excessively warm and cold weather. Five studies have clearly indicated a biomass increment of tea leaves with an increasing $\mathrm{CO}_{2}$ concentration. As a $\mathrm{C} 3$ plant, tea leaves improve photosynthesis with elevated $\mathrm{CO}_{2}$, which is due to an improved maximum rate of carboxylation ( $\mathrm{RuBisCO}$ ) and, RuBP generation, stimulating the biomass production of a tea bush via increased photosynthesis and respiration [106]. An increment of the tea yield with elevated $\mathrm{CO}_{2}$ was further amplified by a rising temperature at high elevations, while the yield increment with elevated $\mathrm{CO}_{2}$ was decreased at low elevations, since the rising temperature pushed the already high temperature into the ceiling temperature range, which is undesirable for physiological processes linked to the tea yield [23]. In addition, the photosynthesis would acclimatize to high $\mathrm{CO}_{2}$ levels, limiting growth factors such as a shortage of nitrogen and other micronutrients, so the increase of the tea yield would not be as great as anticipated [6].

About 50\% (22 out of 42) of the reviewed studies for this topic focused on the impact of temperature fluctuations on the tea yield. Many tea-producing countries reported that increasing temperatures tend to reduce tea yields while reporting beneficial impacts in some tea-growing regions in cooler countries $[23,26,36]$. Atmospheric temperatures beyond the limit of $12{ }^{\circ} \mathrm{C}$ and $30{ }^{\circ} \mathrm{C}$ are less favorable for tea bushes, which reduces tea shoot growth as tea growth is highly temperature-dependent $[107,108]$. The maximum photosynthetic rate of tea is recorded at optimum average ambient temperatures of between $18{ }^{\circ} \mathrm{C}$ and $20^{\circ} \mathrm{C}$ [109]. With an increase in temperature, the evapotranspiration will increase in the tea fields and alter the surface and microclimate around the tea bush, subsequently reducing the tea yield [9]. The quantity and variability of rainfall are crucial, and 17 studies showed that rainfall and seasonal changes will affect tea production. Five studies postulated that a high, low, and uneven distribution of rainfall reduces the tea yield. Rainfall is a major factor that influences the photosynthesis, metabolism, growth, and development of tea bushes. Generally, for successful cultivation, a tea plant requires a minimum annual rainfall of between $1150 \mathrm{~mm}$ and $1400 \mathrm{~mm}$ and an optimum annual rainfall of $2500 \mathrm{~mm}-3000 \mathrm{~mm}[109,110]$. Global warming directly impacts the hydrological cycle and creates ramifications of high rainfall intensities, rainfall variability, floods, and soil erosion in tea fields [94].

It has been reported that a considerable yield reduction results from drought stress [40,41], influencing tea growth, and tends to increase the number of dormant/unproductive buds and eventually reduces the yield [19]. For achieving the optimum tea yield, a radiation intensity from $0.3 \mathrm{cal} / \mathrm{cm}^{2} / \mathrm{min}$ to $0.8 \mathrm{cal} / \mathrm{cm}^{2} / \mathrm{min}$, humidity between $70 \%$ and $90 \%$, and prolonged photoperiods are necessary [45]. There is a reliable source of evidence demonstrating that the amount of solar radiation reaching the Earth has become unstable with climate change over the years [111]. A reduction in sunlight hours resulting from fewer rainy days and more cloudy days with a low light intensity would benefit tea production, as tea is the maximum function of the photosynthetic apparatus adapted to shade conditions. The light quality is also important, affecting tea growth as shorter wavelengths inhibit tea plant growth, and long wavelengths stimulate growth [112].

\subsection{Tea Quality}

Previous studies provide contradictory evidence on how climate change can alter biochemicals present in tea leaves. It is presumed that the chemical composition of tea leaves is a result of multiple genes and hormones, and their interactions mediate biotic and abiotic stressors. The impact of ambient and increased $\mathrm{CO}_{2}$ levels on tea quality is clearly described in 14 recent studies (Table S5). It was found that elevated $\mathrm{CO}_{2}$ significantly increased soluble sugar, theanine, polyphenol, jasmonic acid, and salicylic acid while decreasing caffeine and free amino acids in the tea leaves. However, the literature indicates that elevated $\mathrm{CO}_{2}$ aggravates the susceptibility of tea plants to certain insects and pathogens, posing a serious threat to potential tea production systems.

Ten out of 14 studies $(71 \%)$ showed a decrease in phenolic compound concentrations with a seasonal change from spring to other seasons. Vivid fluctuations of phenolic 
compounds, catechins, and amino acids found with drought, but not the extent of drought periods, reduced the levels of biochemicals. Munivenkatappa et al. [113] showed that drought tea varieties accumulate higher levels of biochemicals. Generally, Camellia sinensis var. assamica (e.g., Assam or Indian tea) is more tolerant to drought than C. sinensis var. sinensis grown in Japan, China, Iran, and Turkey [114]. The supplementation of K+, Kaolin, abscisic acid (ABA), and methyl jasmonate (MeJA) can protect tea plants from drought stress [115].

Previous studies show that there is an inverse association between tea quality and temperature, as the concentrations of catechins, phenols, caffeine, and antioxidants were found to be higher at higher elevations with a cooler temperature $[56,57,116]$. Hence, in the context of climate change, increasing temperatures can deteriorate the quality of tea as a result of warming, particularly at lower altitudes. Nevertheless, one study suggested that a rise in temperature can lead to increased catechin concentrations in tea [117]. Ahmed et al. [11] found that high precipitation is inversely correlated with concentrations of biochemicals having a negative impact on tea quality, diluting the concentration levels of biochemicals. Other climate extremes, such as frost, cyclones, late spring, cold spells, hail, and floods, will also lead to a deterioration in tea quality [118].

High intensity prolonged sunlight causes photoinhibition in tea plants and alters the chemicals present in tea leaves. There is a negative relationship between amino acid levels in tea shoots and sunlight hours, while the amount of amino acid is positively correlated with the relative humidity [54,119]. Multiple genes and hormones mediate tea biochemicals over abiotic factors, and their relationship remains largely unknown [120]. Considering all of the above complex interactions between climatic factors and tea quality, the concentrations and types of certain biochemicals are highly variable, depending on abiotic stresses (Figure S2), reflecting the uncertain nature of tea quality and thus welcoming future research to address this knowledge gap.

From a consumption perspective, the organoleptic parameters of the taste, color, brightness, and flavor of the final tea are governed by secondary metabolites. It is apparent that some secondary metabolites will be enhanced with altered climatic conditions, especially with elevated $\mathrm{CO}_{2}$ and an increase in temperature in cooler regions. Generally, increases in the concentrations of biochemicals are accompanied by an increased tea quality until a specific threshold for consumer demand and consumption. Higher levels of free amino acids (AA) with a certain threshold of total polyphenol (TPC) indicate a better quality of green tea, but these thresholds of amino acids and polyphenols are significantly influenced by climate change. Moreover, the theaflavins and thearubigins are responsible for delivering better quality black tea, and these polyphenol levels are highly climatedependent. However, high levels of specific phenolics are associated with a bitter taste that is typically less preferred by consumers [22]. An array of complicated biochemical and physiological adaptations have progressed in tea plants to allow them to adapt and endure climate change, leaving the quality of tea in the future in jeopardy. Given these alarming circumstances, researchers, concessioners, and related parties should further investigate the dynamics of tea chemicals in the face of climate change, targeting the maintenance of a desirable quality of tea in the future.

\subsection{Climate Suitability for Tea}

Tea's ideal growing conditions are at high risk and expected to change significantly under the altered climate (Figure S2). Given the importance of the ecophysiological requirements for tea plants, their potential distribution and their relationship with climate variables are vital. To date, detailed appraisals of the impacts of the future climate on the suitability of habitats for tea crops are rare. We only found limited studies (Table S6) assessing the climate suitability and spatial distribution of tea crops. Multiple studies demonstrate three possible impacts of climate change on suitability habitats of tea: $\mathrm{s}$ shifting climate suitability of existing tea-growing areas resulting in gains (+) or losses (-) and generating new areas with climate suitability for tea. 
Previous studies have demonstrated how climate change may cause a shift the climate suitability of current tea-growing areas. For example, suitable areas for tea will shift up the altitudinal gradient: those retaining some suitability will see declines of between $20 \%$ to $40 \%$, compared with today's suitability of $60 \%-80 \%$ in Uganda [89]. The major teagrowing counties in China could gradually shift from south to north, and the optimum tea-producing zone in Kenya is projected to move to a higher altitude by 2050, compared to the current climate. Temperature- and precipitation-linked climate changes are the prime factors that impact the potential shift in tea cultivation [81,95]. The rise in the average temperature with global warming could be advantageous for tea plantations located at higher-elevations, as cooler regions would become warmer, but would have a negative effect on lowlands.

Furthermore, increasing minimum temperatures creates possible conditions to grow tea that has traditionally been incompatible with colder climates, whereas existing, wellknown cultivation regions could become undesirable in the future as the temperature gradually becomes too hot [88]. For example, by 2075, the suitability of existing teagrowing regions in Kenya is projected to decrease by $22.5 \%$ [121]. Generally, the reduction in suitable areas for Camellia sinensis var. sinensis was greater than that for Camellia sinensis var. assamica due to its different sensitivity to temperature increases, and Camellia sinensis var assamica is originally native to dry and warmer climate [87].

In addition, some improved tea varieties developed for specific regions could be adopted for cultivation elsewhere, where they would face the same abiotic and biotic stresses. For example, Rivera-Parra and Peña-Loyola [95] identified areas in Ecuador using ecological niche modeling where it is possible to grow Ceylon and Nilgiris tea varieties that will sustain similar ecological niches in the future and have high agricultural potential. This can propel the development of new crop varieties/climate-smart / climate-ready clones, which can sustain the extreme region-specific ecological conditions.

However, it is difficult to expedite a comparative assessment on how climate suitability for tea varies with countries, as previous authors used different approaches, Representative Concentration Pathways (RCPs), and global climate models (GCMs) for their projections. Given the substantial disagreements between the various modeling approaches that are available in the literature, it is better to adopt "methodology ensemble" approaches that provide a much better ensemble projection [87] and overview of the uncertainties involved in such projections than the use of a single method. Efforts should also be made to project the climate suitability for tea by including all countries together, not on an individual country-by-country basis, so that the climatic requirements for tea can be derived more generally, which may allow better projections on future suitability than country-scale analyses. Early warning and monitoring systems should then be established according to the results of predictive models.

Overall, the adverse impacts of climate change on the yield, quality, and climate suitability for tea are greater than the positive impacts. Therefore, an increased understanding and awareness of how climatic factors interact with the tea system is required to identify appropriate adaptation and mitigation strategies, as mentioned in the results section. Compared to the large-scale tea growers, smallholder tea farmers are more susceptible to the adverse impacts of climate extremes such as drought, floods, storms, frost, and heavy rains [101]. In the given context, financial and technical aids should be given to smallholder tea growers while introducing risk management tools to deal with climate change. Importantly, smallholder tea farmers should be encouraged to utilize index-based insurances, mutual funds, microcredits, loans, and other subsidizing measures to cover the risk of economic losses caused by climate change. Farmers need to recognize climate risks and manage them to overcome anticipated consequences and reduce problems of protecting their livelihoods from climate change uncertainties. Some models (e.g., the Ricardian model) could be used to assess the effects of adaptation that describe what would happen to that farm area if it changed into different climate change conditions [122]. As tea farmers are amenable to adapting to climate change, the Ricardian analysis method can be 
applied to tea farms to estimate the value of adaptive responses of climate change. The inclusion of these evidence-based findings and tea farmers' participation in adaptation and mitigation efforts should be considered when formulating synergistic policies to combat the adverse effects of climate change on the tea sector.

\section{Conclusions}

The present systematic review broaches how the current and future climate influences the yield, quality, and climate suitability habitats for tea as there is a dearth of exclusive evidence on the aforementioned facts in the literature. Considering the co-occurrence density map of keywords, most of the studies have been conducted on the impact of climate change on tea quality, followed by tea yield and climate suitability. The historical roots and the most influential papers were identified using RPYS. Based on the yielded facts, tea production would benefit from a temperature increment and elevated $\mathrm{CO}_{2}$, but be negatively impacted by drought, uneven precipitation, and extreme weather events. The positive effect of elevated $\mathrm{CO}_{2}$ and temperature on the tea yield will be reduced if the temperature rises beyond the optimal value, as tea's metabolism is highly thermosensitive. Many studies have shown that the impact of climate-driven changes on tea quality is multidimensional and alters the thresholds of major biochemicals (e.g., the ratio of amino acids to polyphenol), challenging consumers' preferences and jeopardizing the tea quality in the future. Due to fluctuations of climate variables, the loss, gain, and shift of climate suitability for tea habitats will occur. The findings of the present systematic review reflect that the impacts of climate change on tea yield, quality, and suitability habitats are varied and complex. In fact, in certain areas, climate change will be advantageous for tea yield, quality, and distribution, whilst in others it may not be desirable.

The major research gaps found in the present systemic review are the deficiency of studies on the impacts of the future climate on the tea yield and quality and ensemble modeling methods to find climate suitability for tea. In addition, contradictory evidence between studies and a lack of comparable indicators prevented the comparison of the findings of the present review. Future research should capture the complex interactions and realistic responses of tea plants under climate change by providing real-world situations that aid in evaluating the combined effects of multiple climatic factors on tea simultaneously. Multisectoral engagement from governments, industries, farmers, the public sphere, and researchers is vital to strengthen climate innovations, adaptations, and mitigation strategies to tackle the adverse impacts of climate change on the whole tea system. Therefore, the cumulative evidence and records of the present study are essential for designing adaptation and mitigation measures, decision-making, policy formation, and future interventions in the tea sector.

Supplementary Materials: The following are available online at https://www.mdpi.com/article/ 10.3390/agronomy11040619/s1: Figure S1: PRISMA 2009 Flow Diagram; Figure S2: Graphical representation of the overall impact of increased temperature and elevated $\mathrm{CO} 2$ on tea yield and quality as well as the impact of the future climate on climate suitability habitats for tea; Table S1: Details of reviewers and stakeholders who participated in the present systematic review and their expertise; Table S2: Databases, coding and search evidences; Table S3: Details on full-text articles assessed for eligibility for the systematic review; Table S4: Impacts of current and future climate on tea yield; Table S5: Impacts of current and future climate on tea quality; Table S6: Impacts of current and future climate on climate suitability for tea.

Author Contributions: Conceptualization, S.L.J. and L.K.; methodology, S.L.J. and L.K.; software, S.L.J.; systematic analysis, S.L.J. and L.K.; investigation, S.L.J. and L.K.; resources, S.L.J. and L.K.; data curation, S.L.J. and L.K.; writing—original draft preparation, S.L.J.; writing—-review and editing, S.L.J. and L.K.; visualization, S.L.J.; supervision, L.K.; project administration, L.K.; proofreading, S.L.J. and L.K. All authors have read and agreed to the published version of the manuscript.

Funding: This research received no external funding.

Institutional Review Board Statement: Not applicable. 
Informed Consent Statement: Not applicable.

Data Availability Statement: Not applicable.

Acknowledgments: This research was supported by a postgraduate scholarship provided by the University of New England, Australia to the first author. The authors acknowledge Prathibha Kahandage, Bhaggya Samarasinghe, and Chathura Fernando for assisting in screening the relevant articles in the present systematic review.

Conflicts of Interest: The authors declare no conflict of interest.

\section{References}

1. Statista, Internet Usage in India-Statistics \& Facts. 2020. Available online: https:/ /www.statista.com/topics/2157/internet-usagein-india / (accessed on 10 January 2021).

2. Commodities, S. Global Market Report: Tea. 2018. Available online: https://www.iisd.org/system/files/publications/ssi-globalmarket-report-tea.pdf (accessed on 15 November 2020).

3. NASA Global Climate Change. Global Surface Temperature: Vital Signs of the Planet. 2020. Available online: https://climate. nasa.gov/vital-signs/global-temperature/ (accessed on 10 January 2021).

4. Robinson, S. Climate change adaptation in SIDS: A systematic review of the literature pre and post the IPCC Fifth Assessment Report. Wiley Interdiscip. Rev. Clim. Chang. 2020, 11, 653. [CrossRef]

5. Boehm, R.; Cash, S.B.; Anderson, B.T.; Ahmed, S.; Griffin, T.S.; Robbat, A.; Stepp, J.R.; Han, W.; Hazel, M.; Orians, C.M. Association between Empirically Estimated Monsoon Dynamics and Other Weather Factors and Historical Tea Yields in China: Results from a Yield Response Model. Climate 2016, 4, 20. [CrossRef]

6. Li, X.; Zhang, L.; Ahammed, G.J.; Li, Z.-X.; Wei, J.-P.; Shen, C.; Wen-Yan, H.; Zhang, L.-P.; Han, W.-Y. Stimulation in primary and secondary metabolism by elevated carbon dioxide alters green tea quality in Camellia sinensis L. Sci. Rep. 2017, 7, 1-12. [CrossRef]

7. Marx, W.; Haunschild, R.; Bornmann, L. Global Warming and Tea Production-The Bibliometric View on a Newly Emerging Research Topic. Climate 2017, 5, 46. [CrossRef]

8. Reay, D. Climate-Smart Food; Springer Nature: Cham, Switzerland, 2019; p. 201.

9. Chang, K.; Brattlof, M. Socio-Economic Implications of Climate Change for Tea Producing Countries; FAO: Rome, Italy, $2015 ;$ p. 11.

10. Gunathilaka, R.D.; Smart, J.C.; Fleming, C.M. The impact of changing climate on perennial crops: The case of tea production in Sri Lanka. Clim. Chang. 2017, 140, 577-592. [CrossRef]

11. Ahmed, S.; Griffin, T.S.; Kraner, D.; Schaffner, M.K.; Sharma, D.; Hazel, M.; Leitch, A.R.; Orians, C.M.; Han, W.; Stepp, J.R.; et al. Environmental Factors Variably Impact Tea Secondary Metabolites in the Context of Climate Change: A Systematic Review. Front. Plant. Sci. 2019, 10, 939. [CrossRef]

12. Chhogyel, N.; Kumar, L.; Bajgai, Y.; Jayasinghe, L.S. Prediction of Bhutan's ecological distribution of rice (Oryza sativa L.) under the impact of climate change through maximum entropy modelling. J. Agric. Sci. 2020, 158, 25-37. [CrossRef]

13. Elith, J.; Leathwick, J.R. Species Distribution Models: Ecological Explanation and Prediction Across Space and Time. Annu. Rev. Ecol. Evol. Syst. 2009, 40, 677-697. [CrossRef]

14. Waltman, L.; van Eck, N.J.; Noyons, E.C. A unified approach to mapping and clustering of bibliometric networks. J. Informetr. 2010, 4, 629-635. [CrossRef]

15. Moher, D.; Altman, D.G.; Liberati, A.; Tetzlaff, J. PRISMA Statement. Epidemiology 2011, 22, 128. [CrossRef] [PubMed]

16. Hotelling, H. Edgeworth's Taxation Paradox and the Nature of Demand and Supply Functions. J. Political Econ. 1932, 40, 577-616. [CrossRef]

17. Hotelling, H. The Generalization of Student's Ratio. Ann. Math. Stat. 1931, 2, 360-378. [CrossRef]

18. Park, M. Some notes on the effect of drought on the yield of coconut palms. Trop. Agric. 1934, 83, 141-150.

19. Wijeratne, M.A. Vulnerability of Sri Lanka Tea Production to Global Climate Change. Water Air Soil Pollut. 1996, 92, 87-94. [CrossRef]

20. Ahmed, S.; Orians, C.M.; Griffin, T.S.; Buckley, S.; Unachukwu, U.; Stratton, A.E.; Stepp, J.R.; Robbat, A.; Cash, S.; Kennelly, E.J. Effects of water availability and pest pressures on tea (Camellia sinensis) growth and functional quality. AoB Plants 2014, 6 . [CrossRef]

21. Adhikari, U.; Nejadhashemi, A.P.; Woznicki, S.A. Climate change and eastern Africa: A review of impact on major crops. Food Energy Secur. 2015, 4, 110-132. [CrossRef]

22. Ahmed, S.; Stepp, J.R.; Orians, C.; Griffin, T.; Matyas, C.; Robbat, A.; Cash, S.; Xue, D.; Long, C.; Unachukwu, U.; et al. Effects of Extreme Climate Events on Tea (Camellia sinensis) Functional Quality Validate Indigenous Farmer Knowledge and Sensory Preferences in Tropical China. PLoS ONE 2014, 9, e109126. [CrossRef]

23. Wijeratne, M.; Anandacoomaraswamy, A.; Amarathunga, M.; Ratnasiri, J.; Basnayake, B.; Kalra, N. Assessment of impact of climate change on productivity of tea (Camellia sinensis L.) plantations in Sri Lanka. J. Natl. Sci. Found. Sri Lanka 2007, $35,119$. [CrossRef] 
24. Beringer, T.; Kulak, M.; Müller, C.; Schaphoff, S.; Jans, Y. First process-based simulations of climate change impacts on global tea production indicate large effects in the World's major producer countries. Environ. Res. Lett. 2019, 15, 034023. [CrossRef]

25. Rigden, A.J.; Ongoma, V.; Huybers, P. Kenyan tea is made with heat and water: How will climate change influence its yield? Environ. Res. Lett. 2020, 15, 044003. [CrossRef]

26. Sitienei, B.J.; Juma, S.G.; Opere, E. On the Use of Regression Models to Predict Tea Crop Yield Responses to Climate Change: A Case of Nandi East, Sub-County of Nandi County, Kenya. Climate 2017, 5, 54. [CrossRef]

27. Duncan, J.; Saikia, S.; Gupta, N.; Biggs, E. Observing climate impacts on tea yield in Assam, India. Appl. Geogr. 2016, 77, 64-71. [CrossRef]

28. Dutta, R. Monitoring green leaf tea quality parameters of different TV clones grown in northeast India using satellite data. Food Chem. 2013, 139, 689-694. [CrossRef]

29. Raj, E.E.; Ramesh, K.V.; Rajkumar, R. Modelling the impact of agrometeorological variables on regional tea yield variability in South Indian tea-growing regions: 1981-2015. Cogent Food Agric. 2019, 5, 1581457. [CrossRef]

30. Chen, H.; Liu, C.; Liu, C.; Hu, C.; Hsiao, M.; Chiou, M.; Su, Y.; Tsai, H. A Growth Model to Estimate Shoot Weights and Leaf Numbers in Tea. Agron. J. 2019, 111, 2255-2262. [CrossRef]

31. Lou, W.; Sun, K.; Zhao, Y.; Deng, S.; Zhou, Z. Impact of climate change on inter-annual variation in tea plant output in Zhejiang, China. Int. J. Clim. 2021, 41, E479-E490. [CrossRef]

32. Okoth, G.K. Potential Response of Tea Production to Climate Change in Kericho County. Master's Thesis, University of Nairobi Kenya, Nairobi, Kenya, 2011.

33. Han, W.-Y.; Huang, J.-G.; Li, X.; Li, Z.-X.; Ahammed, G.J.; Yan, P.; Stepp, J.R. Altitudinal effects on the quality of green tea in east China: A climate change perspective. Eur. Food Res. Technol. 2017, 243, 323-330. [CrossRef]

34. Rao, G.P. Weather extremes and plantation crops in the humid tropics. Weather 2016, 631, 540.

35. Biggs, E.M.; Gupta, N.; Saikia, S.D.; Duncan, J.M. The tea landscape of Assam: Multi-stakeholder insights into sustainable livelihoods under a changing climate. Environ. Sci. Policy 2018, 82, 9-18. [CrossRef]

36. Nowogrodzki, A. How climate change might affect tea. Nat. Cell Biol. 2019, 566, S10-S11. [CrossRef]

37. Ochieng, J.; Kirimi, L.; Mathenge, M. Effects of climate variability and change on agricultural production: The case of small scale farmers in Kenya. NJAS Wagening. J. Life Sci. 2016, 77, 71-78. [CrossRef]

38. De Costa, W.J.M.; Mohotti, A.J.; Wijeratne, M.A. Ecophysiology of tea. Braz. J. Plant. Physiol. 2007, 19, 299-332. [CrossRef]

39. Leary, N.; Conde, C.; Kulkarni, J. Climate Change and Vulnerability; Earthscan: London, UK, 2009; pp. 358-372.

40. Cheruiyot, E.K.; Mumera, L.M.; Ng'Etich, W.K.; Hassanali, A.; Wachira, F. Polyphenols as Potential Indicators for Drought Tolerance in Tea (Camellia sinensisL.). Biosci. Biotechnol. Biochem. 2007, 71, 2190-2197. [CrossRef]

41. Ng'Etich, W.K.; Stephens, W. Responses of tea to environment in Kenya. 1. Genotype $\times$ environment interactions for total dry matter production and yield. Exp. Agric. 2001, 37, 333-342. [CrossRef]

42. ETP, Tea Production and Consumption Ethical Tea Partnership. 2015. Available online: https://www.ethicalteapartnership.org/ (accessed on 12 July 2020).

43. Ahammed, G.J.; Li, X.; Liu, A.; Chen, S. Physiological and Defense Responses of Tea Plants to Elevated CO2: A Review. Front. Plant. Sci. 2020, 11, 305. [CrossRef]

44. Jiang, Y.; Zhang, S.; Zhang, Q. Effects of elevated atmospheric CO2 concentration on photo-physiological characteristics of tea plant. J. Tea Sci. 2005, 25, 43-48.

45. Li, L.; Wang, M.; Pokharel, S.S.; Li, C.; Parajulee, M.N.; Chen, F.; Fang, W. Effects of elevated CO2 on foliar soluble nutrients and functional components of tea, and population dynamics of tea aphid, Toxoptera aurantii. Plant. Physiol. Biochem. 2019, 145, 84-94. [CrossRef]

46. Wu, Y.; Li, Y.; Fu, X.; Shen, J.; Chen, D.; Wang, Y.; Liu, X.; Xiao, R.; Wei, W.; Wu, J. Effect of controlled-release fertilizer on N2O emissions and tea yield from a tea field in subtropical central China. Environ. Sci. Pollut. Res. 2018, 25, 25580-25590. [CrossRef] [PubMed]

47. AVP, Assignment: Climate Change Challenge. 2016. Available online: https://digital.hbs.edu/platform-rctom/submission/ changing-climates-challenges-to-tata-tea/ (accessed on 15 July 2020).

48. Dutta, R. Climate Change and Its Impact on Tea in Northeast India. J. Water Clim. Chang. 2014, 5, 625-632. [CrossRef]

49. Jayasinghe, H.A.S.L.; Suriyagoda, L.D.B.; Karunarathne, A.S.; Wijeratna, M.A. Modelling shoot growth and yield of Ceylon tea cultivar TRI-2025 (Camellia sinensis (L.) O. Kuntze). J. Agric. Sci. 2018, 156, 200-214. [CrossRef]

50. Matthews, R.B.; Stephens, W. CUPPA-tea: A simulation model describing seasonal yield variation and potential production of tea. 2. Biomass production and water use. Exp. Agric. 1998, 34, 369-389. [CrossRef]

51. Kfoury, N.; Scott, E.R.; Orians, C.M.; Ahmed, S.; Cash, S.B.; Griffin, T.; Matyas, C.; Stepp, J.R.; Han, W.; Xue, D.; et al. Plant-Climate Interaction Effects: Changes in the Relative Distribution and Concentration of the Volatile Tea Leaf Metabolome in $2014-2016$. Front. Plant. Sci. 2019, 10, 1518. [CrossRef]

52. Ahmed, S. Tea and the Taste of Climate Change. Understanding Impacts of Environmental Variation on Botanical Quality. 2014. Available online: https:/ / sites.tufts.edu/teaandclimatechange/files/2014/07/Tea-andthe-Taste-of-Climate-Change.pdf (accessed on 7 June 2017).

53. Bhandari, K.; De, B.; Goswami, T.K. Evidence based seasonal variances in catechin and caffeine content of tea. SN Appl. Sci. 2019, 1, 1740. [CrossRef] 
54. Huang, H.; Kfoury, N.; Orians, C.M.; Griffin, T.; Ahmed, S.; Cash, S.B.; Stepp, J.R.; Xue, D.; Long, C.; Robbat, A. 2014-2016 seasonal rainfall effects on metals in tea (Camelia sinensis (L.) Kuntze). Chemosphere 2019, 219, 796-803. [CrossRef] [PubMed]

55. Xu, H.; Li, L.; Li, Q.; Zhou, L.; Zhu, X.; Chen, F.; Wang, Y.; Fang, W. Effects of elevated atmospheric CO2 concentration and temperature on photosynthesis system and quality components in tea plant. J. Nanjing Agric. Univ. 2016, 39, 550-556.

56. Lee, J.-E.; Lee, B.-J.; Chung, J.-O.; Hwang, J.-A.; Lee, S.-J.; Lee, C.-H.; Hong, Y.-S. Geographical and Climatic Dependencies of Green Tea (Camellia sinensis) Metabolites: A1H NMR-Based Metabolomics Study. J. Agric. Food Chem. 2010, 58, 10582-10589. [CrossRef]

57. Wang, L.Y.; Wei, K.; Jiang, Y.W.; Cheng, H.; Zhou, J.; He, W.; Zhang, C.C. Seasonal climate effects on flavanols and purine alkaloids of tea (Camellia sinensis L.). Eur. Food Res. Technol. 2011, 233, 1049-1055. [CrossRef]

58. Ahmed, S.; Peters, C.M.; Chunlin, L.; Meyer, R.; Unachukwu, U.; Litt, A.; Kennelly, E.; Stepp, J.R. Biodiversity and phytochemical quality in indigenous and state-supported tea management systems of Yunnan, China. Conserv. Lett. 2013, 6, 28-36. [CrossRef]

59. Upadhyaya, H.; Panda, S.K.; Dutta, B.K. CaCl2 improves post-drought recovery potential in Camellia sinensis (L) O. Kuntze. Plant. Cell Rep. 2010, 30, 495-503. [CrossRef]

60. Upadhyaya, H.; Dutta, B.K.; Panda, S.K. Zinc Modulates Drought-Induced Biochemical Damages in Tea [Camellia sinensis (L) O Kuntze]. J. Agric. Food Chem. 2013, 61, 6660-6670. [CrossRef] [PubMed]

61. Cheruiyot, E.K.; Mumera, L.M.; Ng'Etich, W.K.; Hassanali, A.; Wachira, F.; Wanyoko, J.K. Shoot Epicatechin and Epigallocatechin Contents Respond to Water Stress in Tea [Camellia sinensis (L.) O. Kuntze]. Biosci. Biotechnol. Biochem. 2008, 72, 1219-1226. [CrossRef]

62. Wang, W.; Xin, H.; Wang, M.; Ma, Q.; Wang, L.; Kaleri, N.A.; Wang, Y.; Li, X. Transcriptomic analysis reveals the molecular mechanisms of drought-stress-induced decreases in Camellia sinensis leaf quality. Front. Plant. Sci. 2016, 7, 385. [CrossRef]

63. Chakraborty, U.; Dutta, S.; Chakraborty, B. Response of Tea Plants to Water Stress. Biol. Plant. 2002, 45, 557-562. [CrossRef]

64. Wang, Y.; Fan, K.; Wang, J.; Ding, Z.-T.; Wang, H.; Bi, C.-H.; Zhang, Y.-W.; Sun, H.-W. Proteomic analysis of Camellia sinensis (L.) reveals a synergistic network in the response to drought stress and recovery. J. Plant. Physiol. 2017, 219, 91-99. [CrossRef]

65. Cao, P.; Liu, C.; Liu, K. Aromatic constituents in fresh leaves of Lingtou Dancong tea induced by drought stress. Front. Agric. China 2007, 1, 81-84. [CrossRef]

66. Scott, E.R.; Li, X.; Kfoury, N.; Morimoto, J.; Han, W.-Y.; Ahmed, S.; Cash, S.B.; Griffin, T.S.; Stepp, J.R.; Robbat, A.; et al. Interactive effects of drought severity and simulated herbivory on tea (Camellia sinensis) volatile and non-volatile metabolites. Environ. Exp. Bot. 2019, 157, 283-292. [CrossRef]

67. Chaeikar, S.S.; Marzvan, S.; Khiavi, S.J.; Rahimi, M. Changes in growth, biochemical, and chemical characteristics and alteration of the antioxidant defense system in the leaves of tea clones (Camellia sinensis L.) under drought stress. Sci. Hortic. 2020, 265, 109257. [CrossRef]

68. Zhang, X.; Wu, H.; Chen, J.; Chen, L.; Wan, X. Chloride and amino acids are associated with K+-alleviated drought stress in tea (Camellia sinesis). Funct. Plant. Biol. 2020, 47, 398-408. [CrossRef] [PubMed]

69. Lee, J.-E.; Lee, B.-J.; Chung, J.-O.; Kim, H.-N.; Kim, E.-H.; Jung, S.; Lee, H.; Lee, S.-J.; Hong, Y.-S. Metabolomic unveiling of a diverse range of green tea (Camellia sinensis) metabolites dependent on geography. Food Chem. 2015, 174, 452-459. [CrossRef] [PubMed]

70. Zhang, Q.; Shi, Y.; Ma, L.; Yi, X.; Ruan, J. Metabolomic Analysis Using Ultra-Performance Liquid Chromatography-QuadrupoleTime of Flight Mass Spectrometry (UPLC-Q-TOF MS) Uncovers the Effects of Light Intensity and Temperature under Shading Treatments on the Metabolites in Tea. PLoS ONE 2014, 9, e112572. [CrossRef] [PubMed]

71. Zheng, X.Q.; Jin, J.; Chen, H.; Du, Y.Y.; Ye, J.H.; Lu, J.L.; Lin, C.; Dong, J.J.; Sun, Q.L.; Wu, L.Y.; et al. Effect of ultraviolet B irradiation on accumulation of catechins in tea (Camellia sinensis (L) O. Kuntze. Afr. J. Biotechnol. 2008, 7, $3283-3287$.

72. Lu, Z.; Liu, Y.; Zhao, L.; Jiang, X.; Li, M.; Wang, Y.; Xu, Y.; Gao, L.; Xia, T. Effect of low-intensity white light mediated de-etiolation on the biosynthesis of polyphenols in tea seedlings. Plant. Physiol. Biochem. 2014, 80, 328-336. [CrossRef] [PubMed]

73. Sano, S.; Takemoto, T.; Ogihara, A.; Suzuki, K.; Masumura, T.; Satoh, S.; Takano, K.; Mimura, Y.; Morita, S. Stress Responses of Shade-Treated Tea Leaves to High Light Exposure after Removal of Shading. Plants 2020, 9, 302. [CrossRef] [PubMed]

74. Kfoury, N.; Morimoto, J.; Kern, A.; Scott, E.R.; Orians, C.M.; Ahmed, S.; Griffin, T.; Cash, S.B.; Stepp, J.R.; Xue, D.; et al. Striking changes in tea metabolites due to elevational effects. Food Chem. 2018, 264, 334-341. [CrossRef]

75. Jiang, Y.-L.; Zhang, Q.-G.; Zhang, S.-D. Effects of atmospheric CO2 concentration on tea quality. J. Tea Sci. 2006, 26, 299-304.

76. Li, X.; Ahammed, G.J.; Li, Z.; Tang, M.; Yan, P.; Han, W. Decreased biosynthesis of jasmonic acid via lipoxygenase pathway compromised caffeine-induced resistance to Colle-totrichum gloeosporioides under elevated CO2 in tea seedlings. Phytopathology 2016, 106, 1270-1277. [CrossRef] [PubMed]

77. Coll, M.; Hughes, L. Effects of elevated CO2 on an insect omnivore: A test for nutritional effects mediated by host plants and prey. Agric. Ecosyst. Environ. 2008, 123, 271-279. [CrossRef]

78. Kazan, K. Plant-biotic interactions under elevated $\mathrm{CO}_{2}$ : A molecular perspective. Environ. Exp. Bot. 2018, 153, 249-261. [CrossRef]

79. Zhang, C.; Yi, X.; Zhou, F.; Gao, X.; Wang, M.; Chen, J.; Huang, J.; Shen, C. Comprehensive transcriptome profiling of tea leaves (Camellia sinensis) in response to simulated acid rain. Sci. Hortic. 2020, 272, 109491. [CrossRef]

80. Jayasinghe, S.L.; Kumar, L. Climate Change May Imperil Tea Production in the Four Major Tea Producers According to Climate Prediction Models. Agronomy 2020, 10, 1536. [CrossRef] 
81. Jayasinghe, S.L.; Kumar, L. Modeling the climate suitability of tea [Camellia sinensis (L.) O. Kuntze] in Sri Lanka in response to current and future climate change scenarios. Agric. For. Meteorol. 2019, 272-273, 102-117. [CrossRef]

82. Jayathilaka, P.M.S.; Soni, P.; Perret, S.R.; Jayasuriya, H.P.W.; Salokhe, V.M. Spatial assessment of climate change effects on crop suitability for major plantation crops in Sri Lanka. Reg. Environ. Chang. 2011, 12, 55-68. [CrossRef]

83. Kotikot, S.M.; Flores, A.; Griffin, R.E.; Nyaga, J.; Case, J.L.; Mugo, R.; Sedah, A.; Adams, E.; Limaye, A.; Irwin, D.E. Statistical characterization of frost zones: Case of tea freeze damage in the Kenyan highlands. Int. J. Appl. Earth Obs. Geoinf. 2020, 84, 101971. [CrossRef]

84. Deng, S.; Lou, W.; Zhao, Y.; Sun, K.; Chen, K. Evaluation and spatial distribution of tea plant heat injury risk. Geomat. Nat. Hazards Risk 2020, 11, 803-820. [CrossRef]

85. Bo, L.I.; Zhang, F.; Zhang, L.W.; Huang, J.F.; Zhi-Feng, J.I.N.; Gupta, D.K. Comprehensive suitability evaluation of tea crops using GIS and a modified land ecological suitability evaluation model. Pedosphere 2012, 22, 122-130.

86. Ngoc, H.T.H.; Van, T.T.T.; Ha, N.M.; Binh, N.Q.; Tan, M.T. Bioclimatic assessments for tea cultivation in Western Nghe An. Vietnam. J. Earth Sci. 2019, 41, 81-94. [CrossRef]

87. Ranjitkar, S.; Sujakhu, N.M.; Lu, Y.; Wang, Q.; Wang, M.; He, J.; Mortimer, P.E.; Xu, J.; Kindt, R.; Zomer, R.J. Climate modelling for agroforestry species selection in Yunnan Province, China. Environ. Model. Softw. 2016, 75, 263-272. [CrossRef]

88. Eitzinger, A.; Laderach, P. Report of Future Climate Scenarios for Kenya Tea Growing Areas; CIAT: Cali, Colombia; Managua, Nicaragua, 2011.

89. Eitzinger, A.; Läderach, P.; Quiroga, A.; Pantoja, A.; Gordon, J. Future Climate Scenarios for Uganda's Tea Growing Areas; Final Report; CIAT: Cali, Colombia; Managua, Nicaragua, 2011.

90. Jayasinghe, S.L.; Kumar, L.; Sandamali, J. Assessment of Potential Land Suitability for Tea (Camellia sinensis (L.) O. Kuntze) in Sri Lanka Using a GIS-Based Multi-Criteria Approach. Agriculture 2019, 9, 148. [CrossRef]

91. Bhagat, R.; Ahmed, K.Z.; Gupta, N.; Baruah, R.D.; Wijeratne, M.A.; Bore, J.K.; Nyabundi, D.W.; Han, W.; Li, X.; Yan, P.; et al. Report of the Working Group on Climate Change of the FAO Intergovernmental Group on Tea; Technical Report for Food and Agriculture Organization of the United Nations: Rome, Italy, 2016.

92. Kim, Y.-K.; Jombart, L.; Valentin, D.; Kim, K.-O. Familiarity and liking playing a role on the perception of trained panelists: A cross-cultural study on teas. Food Res. Int. 2015, 71, 155-164. [CrossRef]

93. Nakao, K.; Higa, M.; Tsuyama, I.; Lin, C.T.; Sun, S.T.; Lin, J.R.; Chiou, C.R.; Chen, T.Y.; Matsui, T.; Tanaka, N. Changes in the potential habitats of 10 dominant evergreen broad-leaved tree species in the Taiwan-Japan ar-chipelago. Plant. Ecol. 2014, 215, 639-650. [CrossRef]

94. Sombroek, W.; Gommes, R. The climate change-agriculture conundrum. Global Climate Change and Agricultural Production; Wiley: Chichester, UK, 1996; p. 10.

95. Rivera-Parra, J.L.; Peña-Loyola, P.J. Potential high-quality growing tea regions in Ecuador: An alternative cash crop for Ecuadorian small landholders. J. Sci. Food Agric. 2019, 100, 1827-1831. [CrossRef] [PubMed]

96. IPCC. Contribution of Working Groups I, II and III to the Fifth Assessment Report of the Intergovernmental Panel on Climate Change; Climate Change 2014: Synthesis Report; Core Writing Team, Pachauri, R.K., Meyer, L., Eds.; IPCC: Geneva, Switzerland, 2014.

97. Azapagic, A.; Bore, J.; Cheserek, B.; Kamunya, S.; Elbehri, A. The global warming potential of production and consumption of Kenyan tea. J. Clean. Prod. 2016, 112, 4031-4040. [CrossRef]

98. Pramanik, P.; Phukan, M. Assimilating atmospheric carbon dioxide in tea gardens of northeast India. J. Environ. Manag. 2020, 256, 109912. [CrossRef]

99. Muoki, C.R.; Maritim, T.K.; Oluoch, W.A.; Kamunya, S.M.; Bore, J.K. Combating Climate Change in the Kenyan Tea Industry. Front. Plant. Sci. 2020, 11, 339. [CrossRef] [PubMed]

100. Ahmed, S. Toward the Implementation of Climate-Resilient Tea Systems: Agroecological, Physiological, and Molecular Innovations. In Stress Physiology of Tea in the Face of Climate Change; Metzler, J.B., Ed.; Springer: Singapore, 2018; pp. 333-355.

101. Han, W.-Y.; Li, X.; Ahammed, G.J. Stress Physiology of Tea in the Face of Climate Change; Springer: Heidelberg, Germany, $2018 ;$ p. 361.

102. Bank, W. World Development Report 2008: Agriculture for Development; The World Bank: Washington, WA, USA, 2007.

103. Arandara, R.; Gunasekera, S.; Mookerjee, A. Index Insurance: A Viable Solution for Irrigated Farming? The World Bank: Washington, DC, USA, 2019.

104. Zhang, X.; Zhang, C.G.; Wu, J.X.; Chen, H. Risk assessment of yield losses from agro-meteorological disasters in Fujian Province. J. Nat. Disasters 2009, 18, 90-94.

105. Gopalakrishnan, T.; Hasan, K.; Haque, A.; Jayasinghe, S.; Kumar, L. Sustainability of Coastal Agriculture under Climate Change. Sustainability 2019, 11, 7200. [CrossRef]

106. Li, X.; Ahammed, G.J.; Zhang, L.; Yan, P.; Zhang, L.; Han, W.-Y. Elevated Carbon Dioxide-Induced Perturbations in Metabolism of Tea Plants. In Stress Physiology of Tea in the Face of Climate Change; Metzler, J.B., Ed.; Springer: Singapore, 2018 ; pp. $135-155$.

107. Carr, M.K.V.; Stephens, W. Climate, weather and the yield of tea. In Tea; Metzler, J.B., Ed.; Springer: Dordrecht, Netherlands, 1992; pp. 87-135.

108. Jayasinghe, H.; Suriyagoda, L.; Karunaratne, A.; Wijeratne, M. Leaf development and expansion in tea [Camellia sinensis (L.) Kuntze] and their relationships with thermal time: A case study. Trop. Agric. Res. 2015, 25, 450. [CrossRef]

109. Jayasinghe, S.L.; Kumar, L.; Hasan, K. Relationship between Environmental Covariates and Ceylon Tea Cultivation in Sri Lanka. Agronomy 2020, 10, 476. [CrossRef] 
110. Carr, M.K.V. Evaluating the impact of research for development: Tea in Tanzania. Exp. Agric. 1999, 35, 247-264. [CrossRef]

111. Wild, M. Solar Radiationsurfacesolar radiation Versus Climate Change. In Encyclopedia of Sustainability Science and Technology; Meyers, R.A., Ed.; Springer: New York, NY, USA, 2012; pp. 9731-9740.

112. Mohotti, A.; Dennett, M.; Lawlor, D. Electron transport as a limitation to photosynthesis of tea (Camellia sinensis (L.) O. Kuntz): A comparision with sunflower (Helianthus annuus L.) with special reference to irradiance. Trop. Agric. Res. 2000, 12, 1-10.

113. Munivenkatappa, N.; Sarikonda, S.; Rajagopal, R.; Balakrishnan, R.; Nagarathana, C.K. Variations in quality constituents of green tea leaves in response to drought stress under south Indian condition. Sci. Hortic. 2018, 233, 359-369. [CrossRef]

114. Basu Majumder, A.; Bera, B.; Rajan, A. Tea statistics: Global scenario. Inc. J. Tea Sci. 2010, 8, 121-124.

115. Li, H.; Wang, H.; Chen, Y.; Ma, Q.; Zhao, Z.; Li, X.; Chen, X. Isolation and expression profiles of class III PRX gene family under drought stress in Camellia sinensis. Biol. Plant. 2020, 64, 280-288. [CrossRef]

116. Wei, K.; Wang, L.-Y.; Zhou, J.; He, W.; Zeng, J.-M.; Jiang, Y.-W.; Cheng, H. Comparison of catechins and purine alkaloids in albino and normal green tea cultivars (Camellia sinensis L.) by HPLC. Food Chem. 2012, 130, 720-724. [CrossRef]

117. Yao, L.; Caffin, N.; D’Arcy, B.; Jiang, Y.; Shi, J.; Singanusong, R.; Liu, X.; Datta, N.; Kakuda, Y.; Xu, Y. Seasonal Variations of Phenolic Compounds in Australia-Grown Tea (Camellia sinensis). J. Agric. Food Chem. 2005, 53, 6477-6483. [CrossRef]

118. Mwendwa, P.; Giliba, R.A. Climate Change Impacts and Adaptation Strategies in Kenya. Chin. J. Popul. Resour. Environ. 2012, 10, 22-29. [CrossRef]

119. Wei, K.; Wang, L.; Zhou, J.; He, W.; Zeng, J.; Jiang, Y.; Cheng, H. Catechin contents in tea (Camellia sinensis) as affected by cultivar and environment and their relation to chlorophyll contents. Food Chem. 2011, 125, 44-48. [CrossRef]

120. Zeng, L.; Watanabe, N.; Yang, Z. Understanding the biosyntheses and stress response mechanisms of aroma compounds in tea (Camellia sinensis) to safely and effectively improve tea aroma. Crit. Rev. Food Sci. Nutr. 2019, 59, 2321-2334. [CrossRef]

121. Bore, J.K. Impact of climate change on tea and adaptation strategies (Kenya). In Report of the Working Group on Climate Change of the FAO Intergovernmental Group on Tea; Technical Report for Food and Agriculture Organization of the United Nations: Rome, Italy, 2016; pp. 45-60.

122. Bozzola, A.; Perotto, S.; De Angelis, F. Hybrid plasmonic-photonic whispering gallery mode resonators for sensing: A critical review. Analyst 2017, 142, 883-898. [CrossRef] [PubMed] 